\title{
The problems of correlation the life quality and interpersonal dialogue in legal practice of mining regions
}

\author{
Vladimir Zolotukhin ${ }^{1 *}$, Evgenia Stepantsova ${ }^{1}$, Marina Kozyreva ${ }^{1}$, Anastasia Tarasenko ${ }^{1}$, \\ and Alexandr Stepantsov ${ }^{2}$ \\ ${ }^{1}$ T.F. Gorbachev Kuzbass State Technical University, Department of History, Philosophy and Social \\ Sciences, 650000 Kemerovo, 28 Vesennya st., Russian Federation \\ ${ }^{2}$ T.F. Gorbachev Kuzbass State Technical University, Master Course Study, 650000 Kemerovo, 28 \\ Vesennya st., Russian Federation
}

\begin{abstract}
The paper presents an analysis of the impact of life quality at the level of interpersonal dialogue in legal practice of mining regions as the ratio of different subjects there characterizes social-and-cultural environment in general. The attention is given to the fact that the development of social-and-economic potential and independence of the subjects in mining regions in the Russian Federation and other countries makes important the social and cultural factor influencing the development of social stability. The attention is given to the fact that law enforcement on nature and environmental issues depends on the social-and-cultural environment of a particular region and from mentality, legal and environmental awareness, etc. of a particular subject. It was determined that the slowdown in economic growth and an increase of the interests in environmental pollution problems have led not only to the reassessment of the role of coal in China's economic policy, but also touched the problems of social policy, including issues of life quality and law enforcement.
\end{abstract}

\section{Introduction}

Today, the research of coal industry influence on the environment mainly deals with the problems of environmental pollution, inefficient use of land and air pollution. But social and cultural aspect of the activities of coal mining enterprises is not much studied, whereas in terms of social and economic independence of subjects of the Russian Federation the social-and-cultural factor becomes of great importance as it affects the development of social stability. In this case it is advisable to analyze the system of formation of social-andeconomic and social-and-cultural potential of mining regions, as a result of the interaction of these phenomena. Ultimately, these phenomena analysis will allow forming an idea about the quality of life in the region, to identify positive and negative aspects of the influence on it.

*Corresponding author: zvm6@mail.ru 


\section{Materials and methods}

To study the quality of life the works of J. Galbraith, O. Toffler and other scholars were used. To reveal the features of interpersonal dialogue in the law enforcement practice the research made by N. Bobbio, C. Ford, F. Boas and others were analyzed. The scientific literature review helped to cover the most important studies of life quality and its relationship with the specific social-and-cultural environment, including the coal-mining region, as well as the dependence on the dominant type of intercultural dialogue and the law enforcement practice. In the description of current trends and principles of functioning of the various aspects of life quality and interpersonal dialogue in law enforcement the following methods were used: the rational-logical analysis, structural-functional approach, conceptual analysis, historical and logical analysis.

\section{Results and discussion}

The most important factor in the implementation of social-and-cultural and economic integration is a civil society. In this respect it is required adopting the policy of improving life quality not only at the federal level but also at the level of the Russian Federation subjects, at the local level, as well as the impact on individuals. This mechanism requires correlations between "sectoral and territorial production relations taking into account regional and national interests" [1]. As a rule, the Russian Federation subject's specialization is defined by the resource factor that determines, ultimately, its social-andcultural development. Consequently, all areas of regional policy, aimed at improving the level and quality of citizens' life, should be formed on the basis of the real social-andeconomic indicators and factors of development and strategic objectives of regional development.

Considering the subject of the Russian Federation as a member of civil society it is necessary to define the role of the individual in this system. In conditions of democratization of social institutions the individual ceases to be a subject influenced by the State, he (she) is increasingly becoming an independent and active subject of social activity, taking part in the development of civil society. However, a comprehensive regional policy must respond to the needs and interests of society, focusing both on its objective and subjective needs $[2,3]$.

One of the social-and-cultural problems of modern society is the problem of moral development. Actualization of needs and interests of all social-and-economic groups and their subsequent implementation in democracy is possible with high level of law and legal awareness of citizens. The state provides citizens with the statutory level of natural freedom, which gives the latter the possibility to implement social-and-cultural and creative potential. Thus, in our opinion, social-and-cultural environment is formed. In the context of social-and-cultural aspect of the study of life quality social-and-cultural environment is the level of creative abilities of individuals, including the fundamental values, the importance of certain skills and knowledge necessary for the certain activities and performance of individual roles. Social-and-cultural environment directly generates subjective aspect of life quality.

In the study of social-and-cultural environment a special value is acquired by industrial literacy, or industrial culture, the carrier of which is the "engineer-technocrat" - trained and educated employee, meeting the requirements of the technical changes. Within the framework of the theory of technocracy Galbraith notes that a technocrat is an elite manager, having not only specialized knowledge of the natural sciences, but also humanitarian ones. Engineer-technocrat fully meets the requirements of industrial and postindustrial society [4-6]. 
Considering the "life quality", it is worth mentioning the impact of the standard of living vector on the studied area. Today, the economic aspect of the citizens' life and social well-being determines the impact on the cultural perception, the perception of the environment and "green economy" [7-8]. But, in turn, the social-and-economic status of an individual strengthens the cultural experience, or, on the contrary, exacerbates it [9]. In our view, the legal framework creates, delivers and controls the subjective aspect of life quality. In general, it is necessary to enumerate the documents directly regulating mining activities. These acts include: the RF Constitution, the Law of the Russian Federation dated February 21, 1992 № 2395-1 "On Subsurface Resources", the Federal Law dated January 10, 2002 № 7-FL "On Environmental Protection", Tax Code (Chapter 26), the Criminal Code of the Russian Federation (Article 255), the Land Code of the Russian Federation (Article 88).

In addition, a number of regulation documents specifies the requirements for the health and safety protection for the mining industry workers. In particular, Labor legislation, ordinance of the USSR State Labour Committee dated February 5, 1991 № 23 "On approval of the List of industries, jobs, professions and positions, working in which provides additional holiday for underground, hazardous and difficult working conditions for industrial personnel employed in mining enterprises, associations and mine-building, minesinking organizations of metallurgical industry". It provides that summing of the total duration of the additional holiday for harmful and difficult working conditions may not exceed the duration specified in this document. The order of Ministry of Health and Social Development of Russia dated July 6, 2005, № 442 "On approval of the Rate Standards for free providing with certified special clothing, footwear and other personal protective equipment employees engaged in work with harmful and (or) dangerous working conditions, as well as work carried out in special temperature conditions or connected with pollution in the steel industry organizations" (including scale issue of special clothing to employed in mining industries depending on the staff category).

These normative documents, in one way or another, affect not only the life quality of the individual worker in mining industry, but also the qualitative development of a particular region. In terms of regional policy that is accompanied by the activities aimed at the restoration and constant monitoring of the environment, for example, the Round table: "Environmental problems of the Kemerovo Region" (Novokuznetsk, April 6, 2013), "Some indicators of the environment and health of the Kemerovo region population", "Guidelines for the restoration and use of degraded land and the placement of industrial wastes". These documents stated that " $54 \%$ of population in the Kemerovo region live in urban areas with "high" and "very high" level of air pollution".

The impact of the regional specialization on the life quality of citizens on example of the Kemerovo region is the following. In 2015, the share of coal mined in the Kuznetsk Basin was $57.8 \%$ of coal produced in Russia. The share of coal mined in the Kuznetsk Basin in the total volume in Western Siberia in 2015 was $97.7 \%$. In 2015 in the Kuznetsk Basin 215.6 million tons was mined. At the same time the growth rate by 2015 was $187.3 \%$ [10].

As on January 1, 2016 there are 95 coal mining companies (47 mines and 48 open pits) and 50 ore-processing plants and facilities, which employ about 99 thousand people in the Kemerovo Region. The proportion of open coal mining is about $30 \%$.

Despite the large amount of coal production in the Kemerovo region, there are a number of legal, social-and-cultural and environmental problems. The main problem is an uncontrolled issue of license for coal mining to inefficient subsoil users in the region by the Russian Ministry of Natural Resources. The main requirement for coal mining is its quality and safety of production.

The Governor of the Kemerovo region has repeatedly appealed to the Russian Ministry of Natural Resources with the suggestion about termination of the right for using subsurface 
resources by coal enterprises which do not fulfill the conditions of subsoil use. Failure to comply with the license requirements (violation of the initial terms of coal production, the reduction of coal production rates (without the agreement with the regional authority), the requirements of technical projects, failure of reporting to Rosnedra - all this speaks about low culture, including the production and legal one [11]. In this regard it is well to recall the words of Alvin Toffler, who believed that the growing lawlessness, crime, cruelty and arbitrariness witness that the law served humanity well in the past, now turns into an obstacle, and becomes inconsistent [12]. As a result of this problem, there is a threat of disruption of the heating supply for the region's population and social facilities in the area.

Since the mining industry is the main activity in Kuzbass, therefore this sphere provides jobs for a substantial part of its population. The main requirement for coal mining is its quality and safety of production. The Kemerovo region is interested in building new highly productive jobs, corresponding to new production technologies. In connection with this the governor criticizes the delay in putting into operation the new fields, insisting on the withdrawal of retired capacities.

The social-and-cultural aspect is also not less important. From this point of view, the land and its minerals are considered to be valuable for the future generations. Their using practice forms an industrial and technological culture of behavior of different subjects (public authorities, local governments, legal entities, citizens, etc.) operating under the law, but belonging to different social-and-cultural groups. In the end, on the one hand, "cultural diversity endangers the model of society welfare" [13], and on the other it creates the culture as practice [14]. The practice of this legislation depends on the social-and-cultural environment of a particular region (mining regions of Russia or China) and on mentality, legal awareness, environmental awareness, etc. of a particular subject. [15] From this perspective, the issues of state environmental and sanitary control and monitoring, as well as the efficient use and protection of natural resources faced by the various subjects should be solved on the basis of interpersonal and intercultural dialogue and for further reproduction of the population.

The problem of authorities' interaction at the federal and regional levels, increasing the coal production with the permission of the federal government requires a constructive analysis and dialogue between the two levels of government. In addition, it is necessary to organize the interaction "individual-authority" within the professional activity effectiveness. It is not only the interaction of administrative staff and authority, but also social interaction of personnel directly performing its working functions.

Studying the environmental component of coal mining, we should refer to the practice of "energy revolution" in China. Slowing economic growth and an increase of interest to the environmental pollution problems have led not only to reassessment of the role of coal in China's economic policies, but also touched the problems of social policy, including issues of life quality of the population, law enforcement in the area of environmental legislation. The share of coal in energy consumption is expected to decline gradually, as coal-fired power plants will lose their prime importance and give way to nuclear energy.

Culture in the context of the technocracy theory takes the form of not only naturalscience knowledge, but also competent and comprehensive policy of implementation of this knowledge in combination with legal regulations. Moreover, N. Bobbio noted that the negative result of law "off-differentiation" from spirituality leads to the suppressing the individual way for adoption of cultural values, which is the ground for "turning the perspective of civil society development" [16]. Technological culture is a range of industrial and intellectual achievements of people. Industrial society needs require the production to be at higher level of development [17-18], therefore, better and modern knowledge. The development of production, as well as many other areas of human activity, directly depends on the level of science development and scientific achievements. 
We also believe that there is a direct impact of culture on production, which is likely to increase the level of production culture (regardless the emergence of new scientific results and achievements - they may not be at some considering stage). But culture cannot crucially affect the increase of the production level, the emergence of new technologies, methods, etc. This prerogative is given to science and scientific knowledge.

\section{Conclusion}

Thus, the life quality level in the mining region depends not only on social-and- economic stability, but also on the social-and-cultural environment, formed by the interaction of various subjects in the framework of existing legislation. One of the conditions for maintaining social stability is interpersonal, intercultural dialogue aimed at reconciliation of interests and the realization of needs of public authorities, local governments, employers, both public and private sector workers, as well as representatives of human rights organizations, expressing the interests of civil society.

\section{References}

1. V. Trifonov, O. Loyko, D. Nesteruk, S. Zhironkin, E. Strekovtsova, AIP Conf. Proceed., 1800, 050009 (2017)

2. S. Zhironkin, M. Gasanov, O. Zhironkina, E. Taran, SHS Web of Conferences, 28, 01145 (2016)

3. A. Zhavoronok, M. Gasanov, S. Zhironkin, SHS Web of Conferences, 28, 01144 (2016)

4. S. Zhironkin, M. Gasanov, O. Zhironkina, EpSBS, VII, 124-131 (2016)

5. S. Zhironkin, V. Guzyr, EpSBS, VII, 160-166 (2016)

6. M. Gasanov, S. Zhironkin, EpSBS, VII, 117-123 (2016)

7. S. Zhironkin, M. Gasanov, K. Kolotov, EpSBS, XIX, 761-770 (2017)

8. M. Gasanov, S. Zhironkin, M. Hellmer, EpSBS, XIX, 745-752 (2017)

9. S.A. Zhironkin, A.A. Khoreshok, M.A. Tyulenev, G.A. Barysheva, M.C. Hellmer, IOP Conf. Ser.: Mater. Sci. Eng., 142, 012127 (2016)

10. M. Tyulenev, S. Zhironkin, K. Kolotov, E. Garina, Poll. Res., 35:2, 221-227 (2016)

11. S. Zhironkin, M. Gasanov, O. Zhironkina, EpSBS, XIX, 753-760 (2017)

12. A. Toffler, Ecounter, 41(1), 13 (1973)

13. W. van Oorshot, Int. J. Soc. Welfare, 16, 129 (2007)

14. John Gal, Idit Weiss-Gal, Health \& Social Care in the Community, 19(2), 158 (2011)

15. V.M. Zolotukhin, V.A. Gogolin, M.Yu. Yazevich, M.I. Baumgarten, A.V. Dyagileva, IOP Conf. Ser.: Earth and Envir. Sci., 50, 012027 (2017)

16. N. Bobbio, Teoria dell'ordinamento giuridico (Torino, 1960)

17. A.B. Efremenkov, A.A. Khoreshok, S.A. Zhironkin, A.V. Myaskov, IOP Conf. Ser.: Earth Environ. Sci. 50, 012009 (2017)

18. M. Tyulenev, E. Garina, A. Khoreshok, O. Litvin, Y. Litvin, E. Maliukhina, IOP Conf. Ser.: Earth Environ. Sci., 50, 012035 (2017) 